\title{
KAYNAK İLERLEME HIZININ AISI 316L PASLANMAZ ÇELİK LAZER KAYNAKLI BİRLESSTİRMELERİNİN MEKANİK VE MİKROYAPI ÖZELLİKLERİNE ETKİSİ
}

\author{
Ceyhun KÖSE ${ }^{1}$, Ramazan KAÇAR ${ }^{2}$ \\ ${ }^{1}$ Gaziosmanpaşa Üniversitesi, Mühendislik ve Doğa Bilimleri Fakültesi, Makine Müh. Bölümü, Tokat \\ ${ }^{2}$ Karabük Üniversitesi, Teknoloji Fakültesi, İmalat Mühendisliği Bölümü, Karabük \\ ceyhun.kose@gop.edu.tr, rkacar@karabuk.edu.tr
}

(Geliş/Received: 12.06.2014; Kabul/Accepted: 27.02.2015)

\begin{abstract}
ÖZET
$\mathrm{Bu}$ çalışmada, AISI 316L (X2CrNiMo17-12-2) östenitik paslanmaz çelik levhalar $\mathrm{CO}_{2}$ lazer 1şını kaynak yöntemi ile birleştirilmiştir. Kaynak işlemi $\% 50 \mathrm{Ar}+\% 50 \mathrm{He}$ gaz korumalı ortamda, 3500W lazer gücüyle ve 90 $180-270 \mathrm{~cm} / \mathrm{dk}$ farklı kaynak ilerleme hızlarında yapılmıştır. Numuneler otomatik olarak alın alına yatay pozisyonda ve ilave metal kullanılmadan birleştirilmiştir. Kaynaklı birleştirmelerin mekanik özelliklerini belirleyebilmek için çekme, çentik darbe ve üç nokta eğme testleri uygulanmıştır. İlave olarak kaynaklı bağlantıların sertlik ölçümü kaynak yönüne dik kesitten gerçekleştirilmiştir. Mikroyapı karakteristikleri ise Optik mikroskop, Taramalı Elektron Mikroskobu (SEM), Enerji Dağılımlı X-Işını Spektroskopisi (EDS), Elemental haritalama ve X-Işını Difraksiyonu (XRD) vasıtasıyla incelenmiştir. Yapılan bu araştırmanın sonucunda, lazer kaynak ilerleme hızının artmasıyla hızlı soğuma sonucunda mekanik özelliklerin iyileştiği ve kaynak metali mikroyapı morfolojisinin değiştiği tespit edilmiştir.
\end{abstract}

Anahtar Kelimeler: Lazer ışın kaynağı, AISI 316L, kaynak ilerleme hızı, mekanik özellikler, mikroyapı

\section{EFFECT OF WELDING SPEED ON THE MECHANICAL PROPERTIES AND MICROSTRUCTURE OF LASER WELDED AISI 316L STAINLESS STEEL}

\begin{abstract}
In this study, AISI 316L (X2CrNiMo17-12-2) austenitic stainless steel plates were joined with $\mathrm{CO}_{2}$ Laser Beam Welding (LBW) method. The welding process were carried out in $50 \% \mathrm{Ar}+50 \% \mathrm{He}$ shielding gas atmosphere by using $3500 \mathrm{~W}$ laser power for $90-180-270 \mathrm{~cm} / \mathrm{min}$ different welding speeds. The samples were joined autogenously in butt welding position without using filler metal. In order to determine the mechanical properties of welded joints, the tensile, charpy impact and three point bending tests were applied. In addition, the hardness of the welded sample was measured on the cross section. The microstructure characterization of welded samples was carried out using with optical microscope, scanning electron microscope (SEM), energy dispersive X-ray spectroscopy (EDS), elementel mapping and X-ray diffraction (XRD) analysis. As a result of this study, it was found that the mechanical properties of AISI 316L weldment recovered and the microstructure morphology of weld metal altered by increasing laser welding speed due to high cooling rate.
\end{abstract}

Keywords: Laser beam welding, AISI 316L, welding speed, mechanical properties, microstructure

\section{GIRIŞ (INTRODUCTION)}

Mikroyapılarına göre beş kategoride sınıflandırılan paslanmaz çeliklerde nikelin \% 8'in üzerinde olması osteniti oda sıcaklığında kararlı hale getirir ve bu tür paslanmaz çelikler ostenitik paslanmaz çelik olarak isimlendirilir [1]. Bu çelikler mükemmel mekanik özelliklere ve korozyon dayanımına sahiptirler [2-5]. Petro-kimya, arıtma tesisleri ve medikal endüstri gibi pek çok sahada kullanım alanı bulan ostenitik paslanmaz çeliklerin lazer kaynaklı birleştirmeleri endüstrinin dikkatini oldukça çekmektedir. Lazer kaynak yöntemini nitelikli kılan durum, küçük bir alan üzerine odaklanmak suretiyle yüksek güç 
yoğunluğu elde edilerek kullanılabilmesi ve otomasyona uygunluğudur [6]. Lazer, tek renkli, düz, yoğun ve aynı fazlı paralel dalgalar halinde genliği yüksek, başka bir ifade ile suni radyasyon tetiklemesiyle oluşturulan bir 1ş1k demetidir [7]. $\mathrm{CO}_{2}$ lazeri ise; yüksek ve devamlı güç ( $50 \mathrm{~kW}$ 'a kadar) elde edilebilen verimi en yüksek olan bir lazer sistemidir [8-10]. Gaz lazer sistemlerinde aktif ortam olarak $\mathrm{CO}_{2}, \mathrm{~N}_{2}$, He gaz karışımından faydalanılır. Lazer 1şığını oluştururken, $\mathrm{N}_{2}$ ve He molekülleri $\mathrm{CO}_{2}$ moleküllerinin uyarılmasına yardım eder ve 1 şık üretiminin verimini arttırır $[11,12] . \mathrm{CO}_{2}$ lazer kaynak yöntemi düşük 1sı girdisi, yüksek yoğunlaşma enerjisi, yüksek kaynak ilerleme hızı, dar kaynak bölgesi, derin nüfuziyetli birleştirmeler elde edilebilmesi, yüksek mekanik dayanım, düşük distorsiyon ve ilave metal kullanmadan kaynak yapabilme imkanından dolayı geleneksel kaynak yöntemlerinden ayrılır [1315]. Literatürde, paslanmaz çeliklerin lazer kaynaklı birleştirmelerinin mikroyapı ve mekanik özellikleri üzerine detaylı çalışmalar bulunmasına rağmen bu çalışmada kaynak ilerleme hızına bağlı olarak değişen 1S1 girdisinin; $\mathrm{CO}_{2}$ lazer kaynaklı AISI 316L çeliklerin mikroyapı ve mekanik özelliklerine etkisi detaylıca araştırılmıştır.

\section{DENEYSEL ÇALIŞMALAR (EXPERIMENTAL PROCEDURE)}

$\mathrm{Bu}$ çalışmada biyo-malzeme olarak da tercih edilen kimyasal bileşimi Tablo 1'de verilen AISI 316L ostenitik paslanmaz çelik malzeme kullanılmıştır. 95x330x4mm ölçülerinde hazırlanan AISI 316L çelik levhalar Tablo 2'de belirtilen parametrelerle TRUMPF LASERCELL 1005 marka $\mathrm{CO}_{2}$ lazer kaynak makinesiyle (Şekil 1), yatay pozisyonda, önceden hazırlanmış bağlantı kalıbına tutturularak alın alına, ilave metal kullanılmadan ve farklı kaynak ilerleme hızlarında birleştirilmiştir.

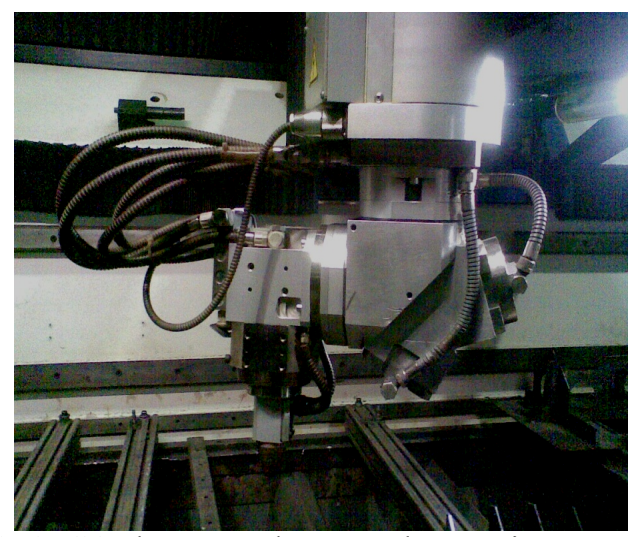

Şekil 1. $\mathrm{CO}_{2}$ lazer 1şın kaynağı düzeneği (The $\mathrm{CO}_{2}$ laser beam welding assembly)

Birleştirmelerin mekanik özelliklerini belirleyebilmek için kaynaklı çekme testi numuneleri ISO 4136: 2012, kaynaksız çekme testi numuneleri ISO 6892-1: 2009, çentik darbe testi numuneleri ISO 9016: 2012, eğme testi numuneleri ISO 5173: 2009 standartlarında Şekil 2a-c'de gösterilen boyutlarda hazırlanmıştır. Birleştirmelerin kaynak dikişlerinde dolgu eksikliğini (underfill) giderebilmek amacıyla kalınlıkları 3

Tablo 1. AISI $316 \mathrm{~L}$ çeliğin kimyasal kompozisyonu (\% ağırlık) (The chemical composition of AISI $316 \mathrm{~L}$ stainless steel (weight $\%)$ )

\begin{tabular}{cccccccccc}
\hline $\mathrm{C} \%$ & $\mathrm{Si}$ & $\mathrm{Mn}$ & $\mathrm{P}$ & $\mathrm{S}$ & $\mathrm{Cr}$ & $\mathrm{Mo}$ & $\mathrm{Ni}$ & $\mathrm{Al}$ & $\mathrm{Co}$ \\
0.013 & 0.528 & 1.859 & 0.052 & 0.0010 & 16.94 & 2.065 & 9.336 & 0.0020 & 0.267 \\
\hline $\mathrm{Cu}$ & $\mathrm{Nb}$ & $\mathrm{Ti}$ & $\mathrm{V}$ & $\mathrm{W}$ & $\mathrm{Pb}$ & $\mathrm{Sn}$ & $\mathrm{Zn}$ & $\mathrm{N}$ & \multirow{2}{*}{$\mathrm{Fe}$} \\
0.248 & 0.0338 & 0.014 & 0.086 & 0.099 & 0.0010 & 0.026 & 0.027 & 0.026 & 68.36 \\
\hline
\end{tabular}

Tablo 2. Kaynak parametreleri (The welding parameters)

\begin{tabular}{|c|c|c|c|c|c|}
\hline $\begin{array}{c}\text { Lazer Gücü } \\
\text { (Watt) }\end{array}$ & $\begin{array}{c}\text { Kaynak Hız } \\
\text { (cm/min) }\end{array}$ & Koruyucu Gaz & $\begin{array}{c}\text { Gaz Debisi } \\
\text { (lt/min) }\end{array}$ & $\begin{array}{c}\text { Odak } \\
\text { Mesafesi } \\
(\mathbf{m m})\end{array}$ & $\begin{array}{c}\text { Isı Girdisi } \\
\text { (kJ/mm) }\end{array}$ \\
\hline 3500 & 90 & $50 \% \mathrm{Ar}+50 \% \mathrm{He}$ & 10 & 200 & 0,233 \\
\hline 3500 & 180 & $50 \% \mathrm{Ar}+50 \% \mathrm{He}$ & 10 & 200 & 0,116 \\
\hline 3500 & 270 & $50 \% \mathrm{Ar}+50 \% \mathrm{He}$ & 10 & 200 & 0,077 \\
\hline
\end{tabular}

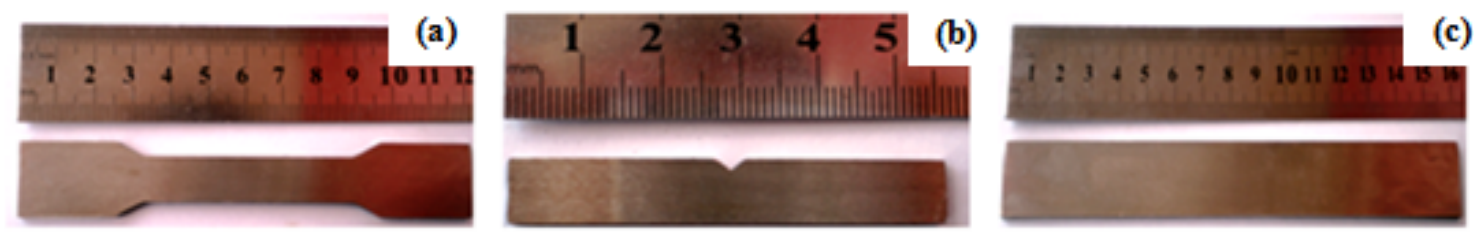

Şekil 2. (a) Çekme, (b) Charpy darbe çentik ve (c) Üç nokta eğme test numunesi ((a) Tensile, (b) Charpy V-notch impact and (c) Three point bending test sample) 


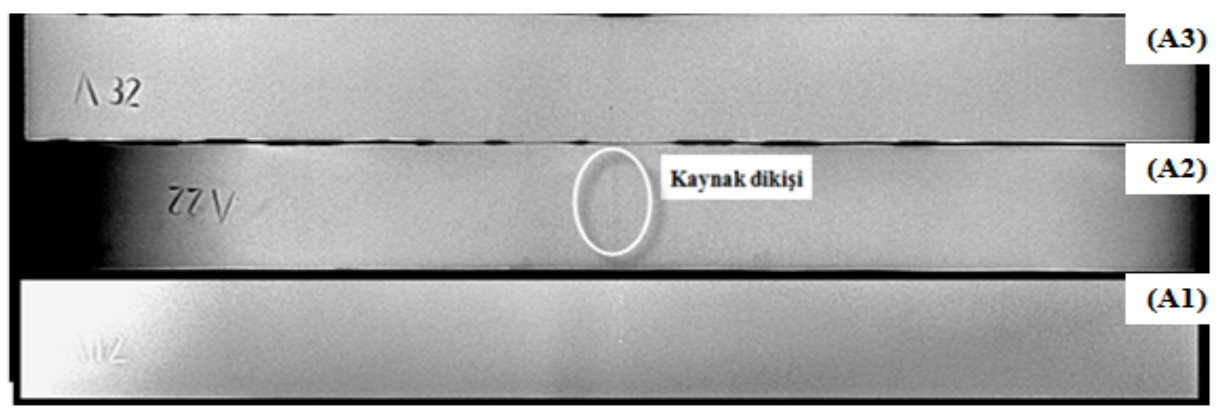

Şekil 3. Radyografik muayene test numuneleri, A1;3500W-90cm/min, A2;3500W-180cm/min, A3;3500W$270 \mathrm{~cm} / \mathrm{min}$ kaynak parametreleri, (Radiographic inspection test samples, $\mathbf{A 1} ; 3500 \mathrm{~W}-90 \mathrm{~cm} / \mathrm{min}, \mathbf{A 2} ; 3500 \mathrm{~W}-180 \mathrm{~cm} / \mathrm{min}$, A3;3500W-270 $\mathrm{cm} / \mathrm{min}$ welding parameters)
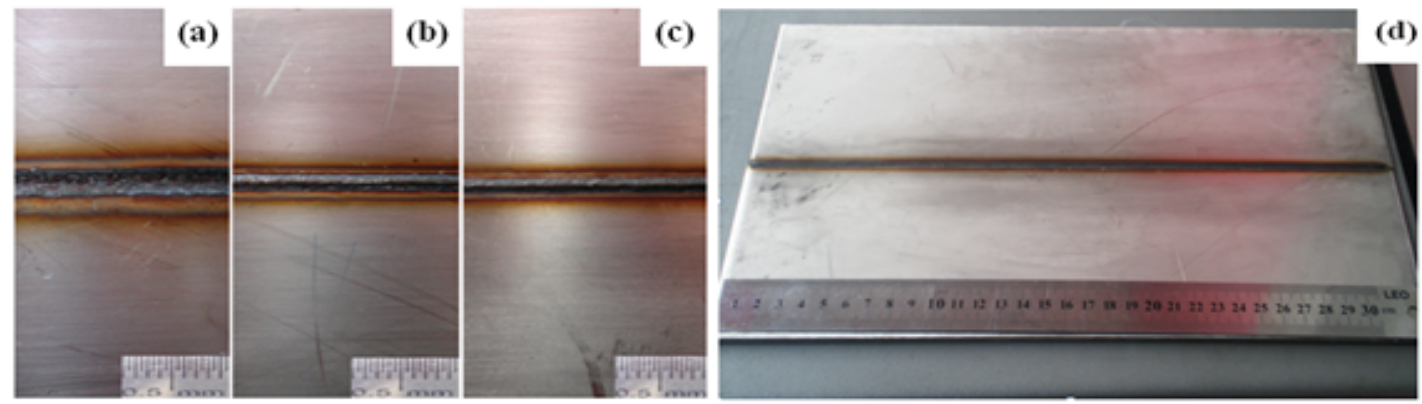

Şekil 4. (a) $3500 \mathrm{~W}-90 \mathrm{~cm} / \mathrm{min}$, (b) $3500 \mathrm{~W}-180 \mathrm{~cm} / \mathrm{min}$, (c) $3500 \mathrm{~W}-270 \mathrm{~cm} / \mathrm{min}$ farklı kaynak ilerleme hızıyla birleştirilen numunelerinin kaynak dikişi görüntüsü, (d) Kaynaklı deney numunesi görüntüsü. (The macrograph of laser weld bead of weldment joined by using different welding speed (a) $3500 \mathrm{~W}-90 \mathrm{~cm} / \mathrm{min}$, (b) $3500 \mathrm{~W}-180 \mathrm{~cm} / \mathrm{min}$, (c) $3500 \mathrm{~W}-$ $270 \mathrm{~cm} / \mathrm{min}$, (d) The macrograph of welded sample)
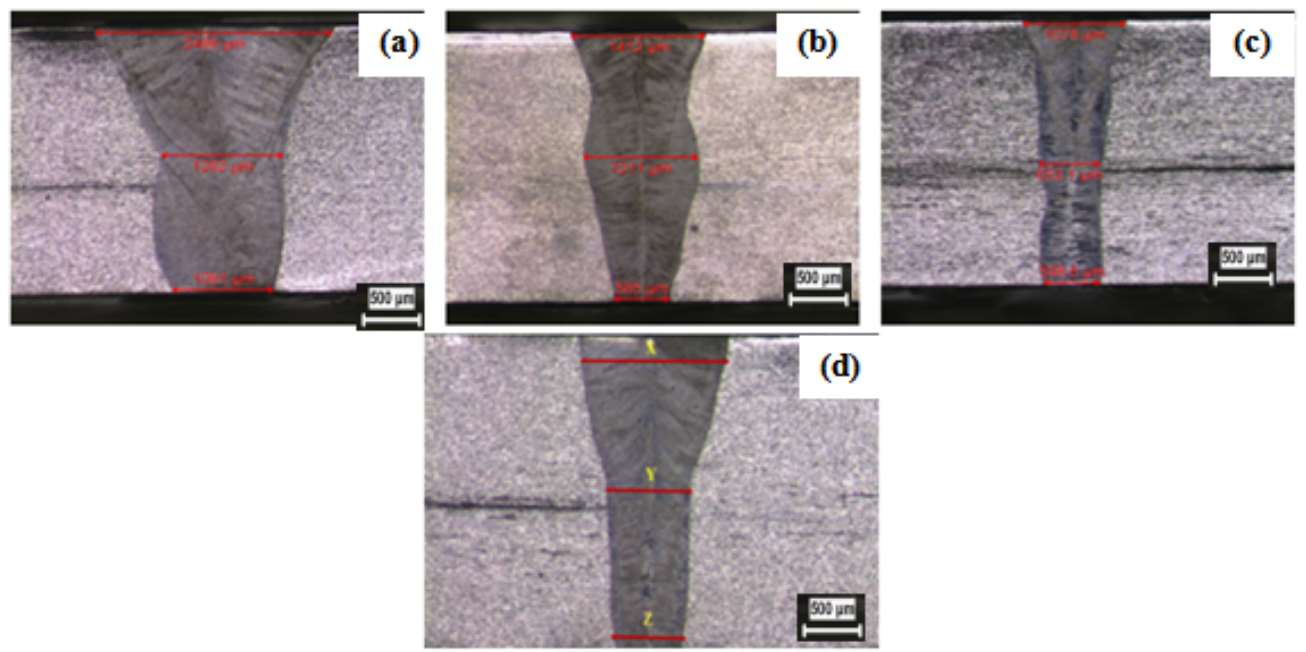

Şekil 5. (a) $3500 \mathrm{~W}-90 \mathrm{~cm} / \mathrm{min}$, (b) $3500 \mathrm{~W}-180 \mathrm{~cm} / \mathrm{min}$, (c) $3500 \mathrm{~W}-270 \mathrm{~cm} / \mathrm{min}$ farklı kaynak ilerleme hızlarında birleştirilen numunelerin kaynak dikiş profili, (d) Dikiş boyutu ölçüm alanı, (The cross section weld bead profile of samples joined at different welding speed), (a) $3500 \mathrm{~W}-90 \mathrm{~cm} / \mathrm{min}$, (b) $3500 \mathrm{~W}-180 \mathrm{~cm} / \mathrm{min}$, (c) $3500 \mathrm{~W}-270 \mathrm{~cm} / \mathrm{min}$ ), (d)The weld bead dimension measurement area)

mm'ye indirilmiştir. Hataları minimize etmek amacıyla her bir şart için 3 numune hazırlanmıştır. Çekme ve üç nokta eğme testi SHIMADZU AG-IS marka $100 \mathrm{kN}$ kapasiteli çekme test cihazında 5 $\mathrm{mm} / \mathrm{dk}$ ilerleme hızında, darbe çentik testi ise standart altı hazırlanan numunelere oda sicaklığında OHR\&FEDERAF AG PSW 13/15 marka deney cihazıyla gerçekleştirilmiştir. Sertlik ise elektrolitik dağlanan (10g oksalik asit $\left.+100 \mathrm{ml} \mathrm{saf} \mathrm{H}_{2} \mathrm{O}\right)$ numune üzerinde SHIMADZU marka ölçüm cihazında uca
$200 \mathrm{~g}$ yük uygulanarak ölçülmüştür. Mikroyapı incelemeleri 5X-100X büyütmeli OLYMPUS marka optik mikroskop, JEOL JSM 6060 LV marka taramalı elektron mikroskobu (SEM) ve (EDS) donanımı ile gerçekleştirilmiştir. XRD analizi $40 \mathrm{kV}$ gerilim ve 40 $\mathrm{mA}$ akım değerlerinde, $\mathrm{Cu} \mathrm{K} \alpha$ radyasyon ışınımı kullanılarak 2/dk. tarama hızı ile Rigaku DMAX2200/PC marka cihazdan yararlanılarak gerçekleştirilmiştir. Birleştirmelerin radyografik muayenesi eğme numuneleri üzerinde, $90 \mathrm{kV}, 30 \mathrm{~mA}$ 
enerji ile 45 sn pozlama süresinde, film kaynak uzaklığı ffd:1000 mm olacak şekilde X 1şınları uygulanarak gerçekleştirilmiştir.

\section{SONUÇLAR VE TARTIŞMA (RESULTS AND DISCUSSION)}

\subsection{Tahribatsız Radyografik Muayene Testi (Non- Destructive Radiographic Inspection Test)}

Birleştirmelerde süreksizlik (gaz boşluğu, çatlak vb.) oluşup oluşmadığını kontrol etmek amacıyla, rastgele seçilen deney numuneleri üzerinde radyografik muayene işlemi uygulanmış elde edilen filmler Şekil 3'de gösterilmiştir.

Birleştirmelerin genelinde ana malzeme, ITAB ve kaynak metalinde herhangi bir hataya rastlanmamıştır. $\mathrm{Bu}$ sonuçlar, farklı kaynak ilerleme hızında birleştirilen AISI 316L paslanmaz çeliklerin hatasız ve başarılı bir şekilde birleştirildiğine işaret etmektedir.

\subsection{Makroyapı İncelemesi (Macrostructure} Examination)

Şekil 4a-c'den üç farklı ilerleme hızıyla birleştirilmiş numunelerinin artan kaynak hızıyla dikiş boyutlarının ve kaynak dikişi etrafindaki renklenmenin daraldığ görülmektedir. Ayrıca kaynak dikişinde ilave metal kullanılmamasına bağlı olarak dolgu eksikliği meydana geldiği görülmektedir (Şekil a ve d). Yüksek enerjili ışınla ilave metal kullanılmadan elde edilen birleştirmelerde kaynak dikişinde dolgu eksikliği oluşabildiği rapor edilmiştir [16,17].

Farklı kaynak ilerleme hızına bağlı olarak değişiklik gösteren kaynak dikiş boyutları (Şekil 5a-d'de) gösterilmiş ve sonuçlar Tablo 3'de verilmiştir. Bulgular, artan kaynak ilerleme hızına bağlı olarak azalan 1sı girdisinden dolayı kaynak metali genişliğinin daraldığına işaret etmektedir. Çünkü kaynak ilerleme hızı ısı girdisine ters yönde etki eden kaynak parametrelerinden birisidir.

\subsection{Mikroyapı İncelemeleri (Microstructure Examination)}

Kaynaklı numunelerin ana malzemeleri eşeksenli ostenit tanelerinden oluştuğu ve bazı tanelerde ikizlenmelerin yanı sıra bantlaşmalar Şekil 6(a-1)'da görülmektedir. Şekil 6 (b,e ve h)'den görüldüğü üzere lazer kaynak yöntemine bağlı olarak hızlı soğuma sonucunda ana malzeme üzerinde çok dar bir ITAB oluşmuştur.

Yüksek enerji yoğunluklu, ancak düşük 1sı girdili yöntemlerle birleştirilen paslanmaz çeliklerde dar bir ITAB oluştuğu başka araştırmacılar tarafindan da rapor edilmiştir [18-22].

Kaynak metali mikroyapısının soğuma rejimine bağlı olarak ostenit matris içerisinde karıncalanma (vermicular), çatısal (skeletal), ve çıta (lath) tipi morfolojili delta ferrit fazlarından oluşur $[10,18,19,23]$. Ostenit matris içerisinde \%3-10 delta ferrit fazı bu çeliklerin katılaşma çatlamasına karşı direncini arttırır.

İlerleme hızının kaynak metali mikroyapı morfolojisi üzerindeki etkisi Şekil 6 (e, f ve 1) görülmektedir. Ostenitik paslanmaz çeliklerin kaynak metalinin $\delta$ ferrit miktarı ve morfolojisi, katılaşma biçimi ve soğuma oranıyla ilişkilidir [24-32]. Kaynak ilerleme hızındaki değişim soğuma rejimini dolayısıyla katılaşma sürecini etkiler. Bunun neticesinde de kaynak metalindeki $\delta$-ferrit miktarı değişmiş ve morfolojisinde karıncalanma, çatısal ve çıta tipi ferrit oluşumu gibi değişiklikler göstermiştir.

Ostenitik paslanmaz çelik kaynak metalinin katılaşma sürecinde ve kat1-katı dönüşümünde dört farklı dönüşüm olma ihtimali olduğu rapor edilmiştir $[10,30,33]$. Bunlardan birisi de delta ferrit fazının birincil dönüşüm fazı olarak başladığı katılaşma biçimidir.

Ferritin birincil faz olarak katılaştığı dönüşüm sonucunda ferrit-ostenit dönüşümünden karıncalanma, çatısal ve/veya çıta tipi ferrit morfolojisi meydana gelir. Örneğin; kaynak soğuma oranının orta, $\mathrm{Cr}_{\text {eş }} / \mathrm{Ni}_{\mathrm{eş}}$ oranı ise düşük seviyede olduğu fakat hala ferritostenit alanında bulunulduğunda karıncalanma ve çatısal tip ferrit morfolojisi oluşur.

Çatısal tip ferrit morfolojisindeki ferrit-ostenit tane sınırlarındaki girinti çıkıntılardan dolayı kükürt ve fosfor gibi katışkı elementlerinin bu alt tane sınırlarını 1slatması ve oluşabilecek çatlağın bu girintili çıkıntılı ferrit-ostenit arayüzeyinde ilerlemesi zordur.

Tablo 3. Kaynak dikiş profili (The weld bead profile)

\begin{tabular}{cccc}
\hline Numune no & $\begin{array}{c}\mathbf{X} \\
(\boldsymbol{\mu m})\end{array}$ & $\begin{array}{c}\mathbf{Y} \\
(\boldsymbol{\mu m})\end{array}$ & $\begin{array}{c}\mathbf{Z} \\
(\boldsymbol{\mu m})\end{array}$ \\
\hline $\begin{array}{c}\mathbf{A 1} ; 3500 \mathrm{~W}- \\
90 \mathrm{~cm} / \mathrm{min}\end{array}$ & 2486 & 1282 & 1061 \\
\hline $\begin{array}{c}\mathbf{A 2} ; 3500 \mathrm{~W}- \\
180 \mathrm{~cm} / \mathrm{min}\end{array}$ & 1412 & 1211 & 585 \\
\hline $\begin{array}{c}\mathbf{A 3} ; 3500 \mathrm{~W}- \\
270 \mathrm{~cm} / \mathrm{min}\end{array}$ & 1078 & 653 & 598 \\
\hline
\end{tabular}



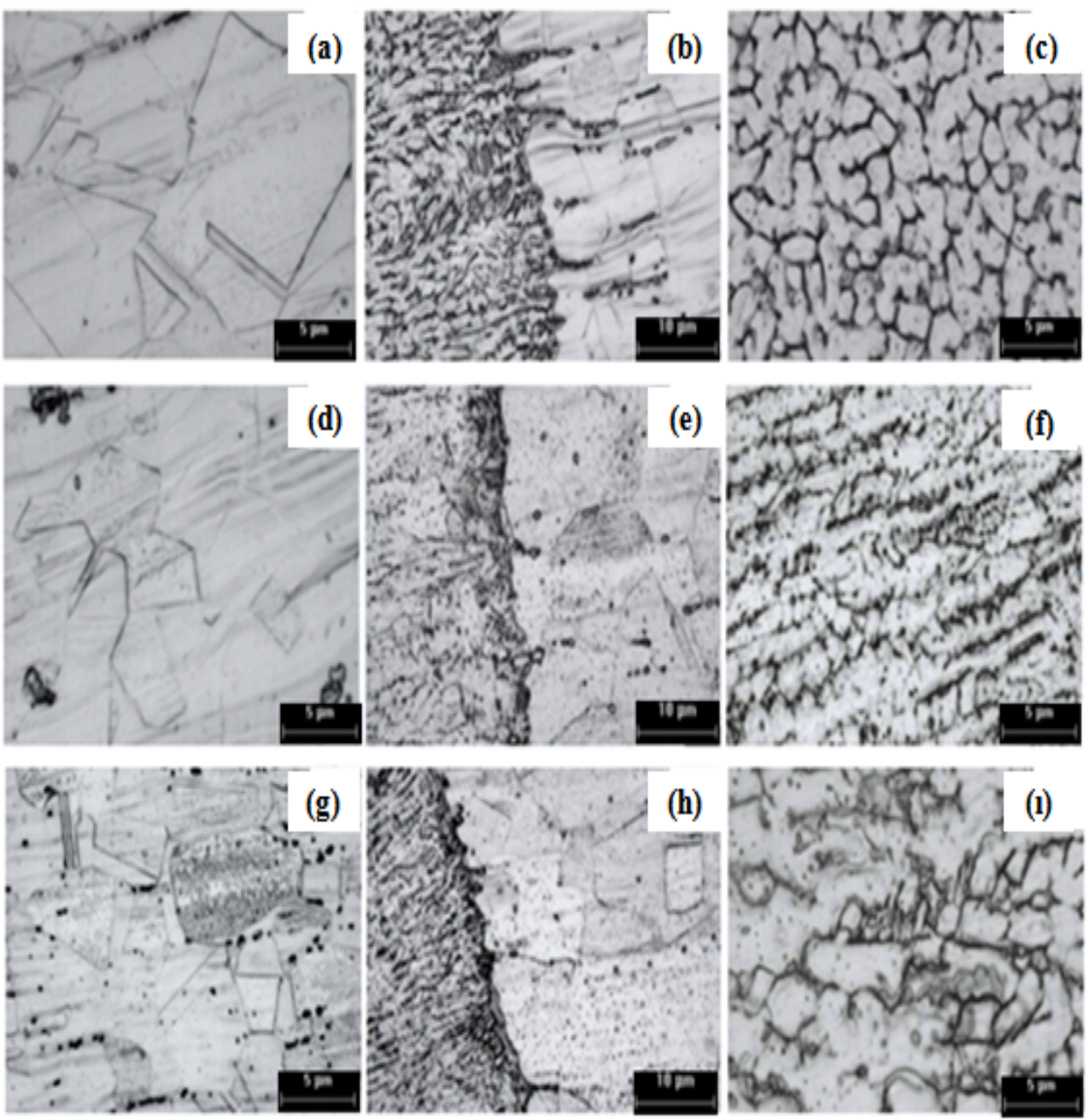

Şekil 6. Kaynaklı birleştirmelerin mikroyapı görüntüleri (a) $3500 \mathrm{~W}-90 \mathrm{~cm} / \mathrm{min}$, ana malzeme (1000X), (b) ITAB (500X), (c) kaynak metali (1000X), (d) $3500 \mathrm{~W}-180 \mathrm{~cm} / \mathrm{min}$, ana malzeme (1000X), (e) ITAB (500X), (f) kaynak metali (1000X), (g) $3500 \mathrm{~W}-270 \mathrm{~cm} / \mathrm{min}$, ana malzeme (1000X), (h) ITAB (500X), (I) kaynak metali (1000X), (Microstructure of welded samples (a) $3500 \mathrm{~W}-90 \mathrm{~cm} / \mathrm{min}$, Base material (1000X), (b) HAZ (500X), (c) weld metal (1000X), (d) 3500W-180cm/min, Base material (1000X), (e) HAZ (500X), (f) weld metal (1000X), (g) 3500W-270cm/min, Base material (1000X), (h) HAZ (500X), (1) weld metal (1000X))

$\mathrm{Bu}$ sebeple çatısal tip ferrit morfolojisine sahip kaynak metali yapısının katılaşma çatlağına karşı daha dirençli olması beklenir [33]. Ancak soğuma hızı ve $\mathrm{Cr}_{\mathrm{es}} / \mathrm{Ni}_{\mathrm{es}}$ oranının arttığında ferrit-ostenit dönüşümü sırasında sınırlı difüzyondan dolayı çatısal tipi ferrit yerine çıta tipi ferrit morfolojisi oluşur.

Hatta katılaşmanın, soğuma rejimi lazer kaynağı gibi oldukça yüksek olan uygulamalarda ferrit ostenit dönüşümünün difüzyonsuz masif dönüşüm şeklinde olabileceği ve birincil katılaşmanın ferritten ostenite bile kayabileceği ifade edilmiștir [33]. Ayrıca, birleştirmeler üzerinde SEM çalışmaları yapılmış ve ana malzeme, kaynak metali ve ITAB'dan noktasal EDS analizi yapılmış ve sonuçlar Şekil 7a-c'de gösterilmiştir.Ilave olarak kaynak metalinden elementel haritalama yöntemi ile analizler yapılmış ve sonuçlar Şekil 8a-c'de gösterilmiştir. Sırasıyla Şekil $7 \mathrm{a}-\mathrm{c}$ ve Şekil 8a-c'de gösterilen EDS analiz ve elementel haritalama sonuçları bu malzemeye ait spektral analiz sonuçlarıyla (Tablo 1) uyumlu bulunmuştur. Kaynaktan dolayı belirgin alaşım elementi kayıplarının yaşanmadığı ve kaynak metalinde alaşım elementi miktarlarında değişim meydana gelmediği tespit edilmiştir.

Deney numunelerinin, ana malzeme, ITAB ve kaynak metali bölgelerinde meydana gelebilecek oluşumlar XRD yöntemi ile $5^{\circ}<2 \theta<105^{\circ}$ ve $30^{\circ}<2 \theta<105^{\circ}$ aralığında incelenmiş ve sonuçlar Şekil 9'da grafiksel olarak gösterilmiştir. Grafikteki ana malzemeye ait pikler ile farklı kaynak ilerleme hizlarıyla birleștirilmiş numunelerin pikleri karşılaştırıldığında, kaynaklı numune piklerinin daha keskin ve sik olduğu, ayrıca pik şiddetlerinde artışlar görülmektedir. $\mathrm{Bu}$ durum, kaynak ilerleme hızına bağlı 1sı girdisi değişimiyle numunelerin kristal kafes parametrelerinde oluşan değişikliklerle ilişkilendirilebilir. 


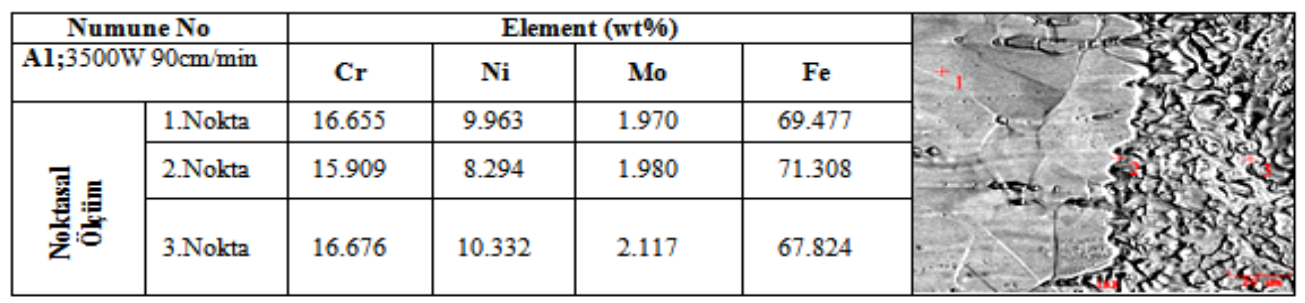

(a)

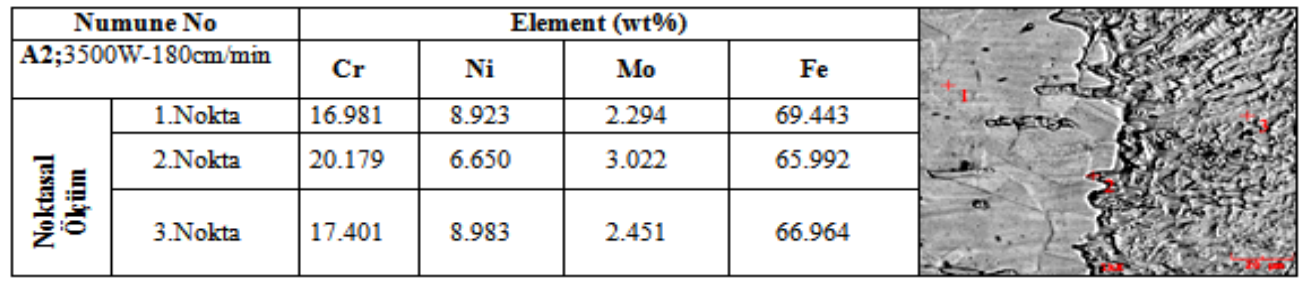

(b)

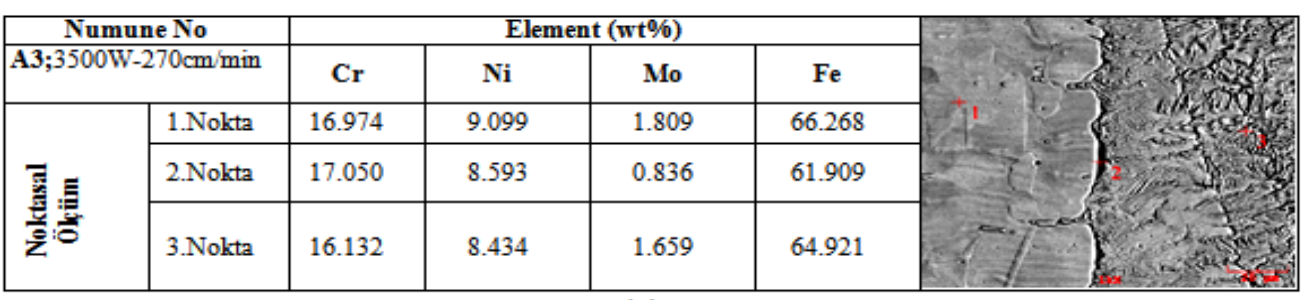

(c)

Şekil 7. Numunelerin EDS analiz sonuçları (a) $3500 \mathrm{~W}-90 \mathrm{~cm} / \mathrm{min}$, (b) $3500 \mathrm{~W}-180 \mathrm{~m} / \mathrm{min}$, (c) $3500 \mathrm{~W}$ $270 \mathrm{~cm} / \mathrm{min}$, (EDS analysis results of samples, (a) $3500 \mathrm{~W}-90 \mathrm{~cm} / \mathrm{min}$., (b) $3500 \mathrm{~W}-180 \mathrm{~cm} / \mathrm{min}$., (c) $3500 \mathrm{~W}-270 \mathrm{~cm} / \mathrm{min}$ )

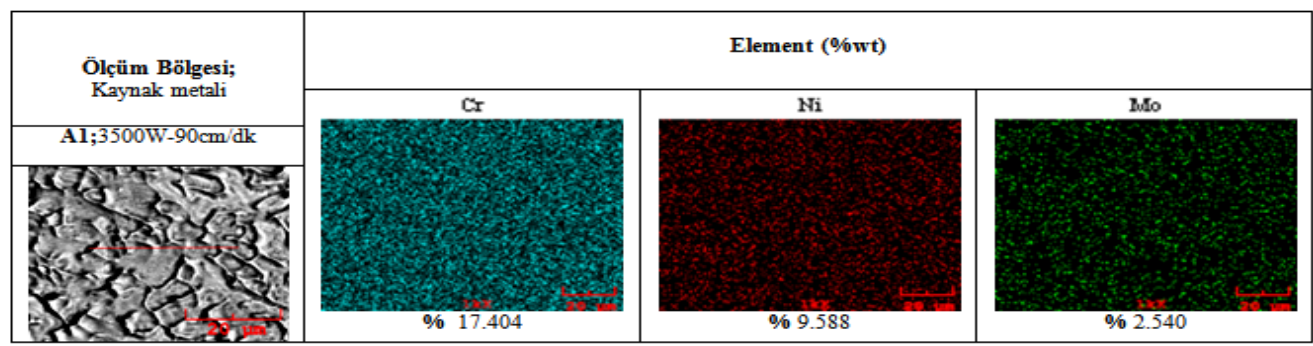

(a)

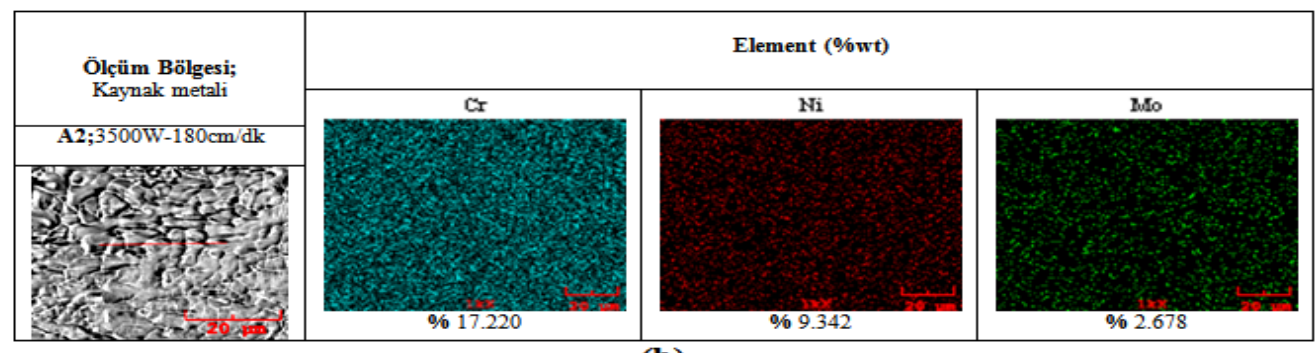

(b)

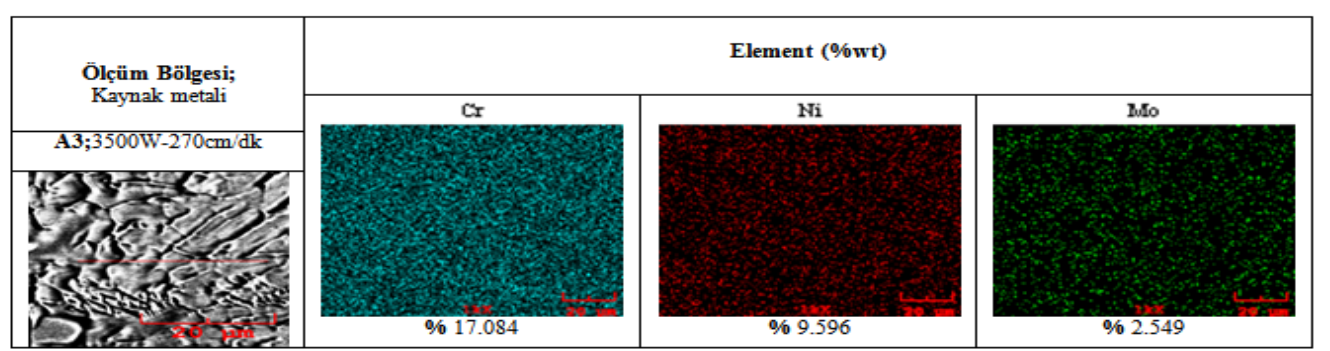

(c)

Şekil 8. Numunelerinin elemental haritalama analiz sonuçları (a) $3500 \mathrm{~W}-90 \mathrm{~cm} / \mathrm{min}$, (b) $3500 \mathrm{~W}-180 \mathrm{~m} / \mathrm{min}$, (c) $3500 \mathrm{~W}-270 \mathrm{~cm} / \mathrm{min}$, (Elemental mapping analysis result of samples, (a) $3500 \mathrm{~W}-90 \mathrm{~cm} / \mathrm{min}$, (b) $3500 \mathrm{~W}-180 \mathrm{~cm} / \mathrm{min}$, (c) $3500 \mathrm{~W}-270 \mathrm{~cm} / \mathrm{min}$ ) 


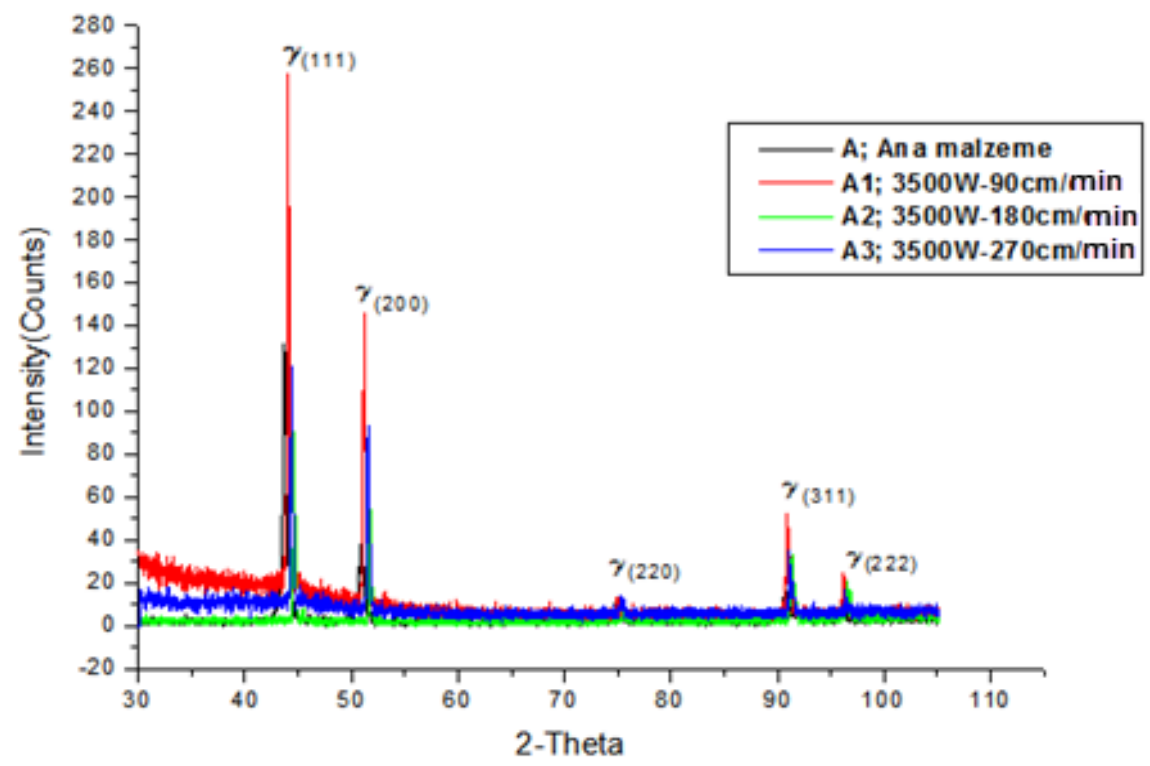

Şekil 9. XRD analizi sonucu (XRD analysis result)

Ancak difraksiyonun elde edildiği düzlemlerin indis değerlerinin tümünün tek veya tümünün çift sayı oluşu bu malzemenin östenitik yapıda olduğuna işaret etmektedir. XRD grafiklerinde ITAB ve kaynak metalinde ikincil faz çökeltileri, intermetalik sigma (s) fazı, krom-karbür çökelmesi $\left(\mathrm{M}_{23} \mathrm{C}_{6}\right)$ gibi oluşumlar tespit edilmemiştir. Düşük 1S1 girdisi ve yüksek enerji yoğunluğuna bağlı olarak hızlı soğuma neticesinde yeterli zaman olmadığ 1 için ikincil faz oluşumların meydana gelmesi beklenemez. Fakat XRD analiziyle az miktarlarda oluşan ikincil faz oluşumlarının tespit edilememesi de göz ardı edilmemelidir.

\section{4. Çekme Deneyi (Tensile Testing)}

Farklı kaynak ilerleme hızlarında birleştirilen numunelerin ve ana malzemenin mekanik özelliklerini belirlemek için çekme testi uygulanmış ve sonuçlar Şekil 10'da gösterilmiştir. Çekme deneyi sonuçları incelendiğinde, çalışmada kullanılan AISI 316L ostenitik paslanmaz çeliğin ortalama akma dayanımı $298 \mathrm{MPa}$, çekme dayanımı $605 \mathrm{MPa}$, uzama değeri \%59 olarak bulunmuştur. En düşük kaynak ilerleme hızıyla birleştirilen $(3500 \mathrm{~W}-90 \mathrm{~cm} / \mathrm{min})$ numunenin akma dayanımı $315 \mathrm{MPa}$, çekme dayanımı $616 \mathrm{MPa}$, uzama değeri \%57 olarak tespit edilmiştir. En yüksek kaynak ilerleme hızıyla birleştirilen (3500W$270 \mathrm{~cm} / \mathrm{min}$ ) numunenin akma dayanımı $319 \mathrm{MPa}$, çekme dayanımı $629 \mathrm{MPa}$, uzama değeri \%56 olarak bulunmuştur. Çalışmada $3500 \mathrm{~W}-180 \mathrm{~cm} / \mathrm{min}$ ilerleme hızıyla elde edilen numunenin akma dayanımı 311 $\mathrm{MPa}$, çekme dayanımı $619 \mathrm{MPa}$, uzama değeri ise $\% 48$ olarak tespit edilmiştir.

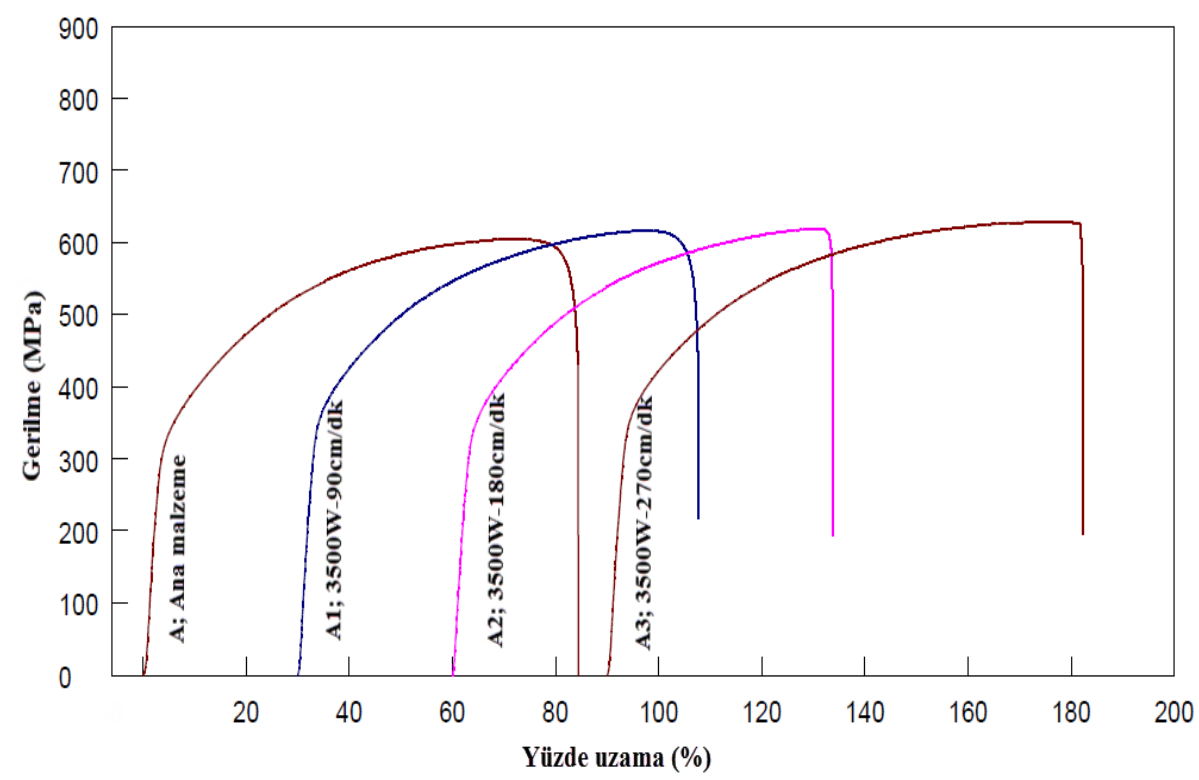

Şekil 10. Numunelerin gerilme-uzama grafiği (Stress-strain graphic of samples) 
Kaynaklı numunelerin çekme dayanımı ana malzemenin çekme dayanımından az da olsa daha yüksek olduğu Şekil 10'dan görülmektedir. Sonuçlar tüm kaynak ilerleme hızları için kaynak edilebilirlik açısından kabul edilebilir değerlerdedir. İlerleme hızının artmasıyla birleştirmelerin çekme dayanımlarının az da olsa iyileştiği görülmektedir. $\mathrm{Bu}$ durum hatasız kaynak dikişlerine, ITAB daralmasına ve kaynak metali mikroyapı morfolojisine (ostenit matris içerisinde karıncalanma, çatısal veya çıta tipi ferrit fazına) atfedilebilir. Yüksek dayanım elde edilmesinde, tam nüfuziyetli kaynak dikişleri, mikroçatlak ve porozite gibi hatalar oluşmaması ve ITAB daralmasının etkili olduğu rapor edilmiştir $[6,12]$.

\section{5. Çentik Darbe Deneyi (Charpy V-Notch Impact Testing)}

Kaynaklı birleştirmelerin ani bir kuvvet karşısındaki davranışlarını belirlemek için darbe testi uygulanmış sonuçlar grafiksel olarak Şekil 11'de gösterilmiştir. Sonuçlardan, darbe dayanımının kaynak ilerleme hızı artışına, diğer bir ifadeyle kaynak 1sı girdisi azalmasına bağlı olarak belirgin olarak arttığı tespit edilmiştir. Soğuma rejimine bağlı olarak kaynak metalinde delta ferrit fazının miktarının değişimi ve düşük soğuma rejiminde oluşan karıncalanma tipi ferrit yerini yüksek soğuma rejiminde çatısal ve çıta tipi ferrit morfolojisine birakarak kaynak metalinin tokluğunda iyileşmeye neden olduğu düşünülmektedir. Yüksek enerji yoğunluklu düşük 1s1 girdili kaynaklarda birleştirme üzerinde kalıntı gerilimlerin daha az oluşumu tokluk artışının bir diğer sebebi olabilir. İbrahim ve arkadaşları, tokluk düşüşünü $\delta$-ferrit oranının artışına bağlamış ve artan kalıntı gerilmelerin darbe enerjisi değerlerini azalttığını rapor etmiştir [34]. Darbe çentik numunelerinin kırılma yüzeyleri incelenmiş ve sonuçlar Şekil 12a-c'de gösterilmiştir. Numunelerin

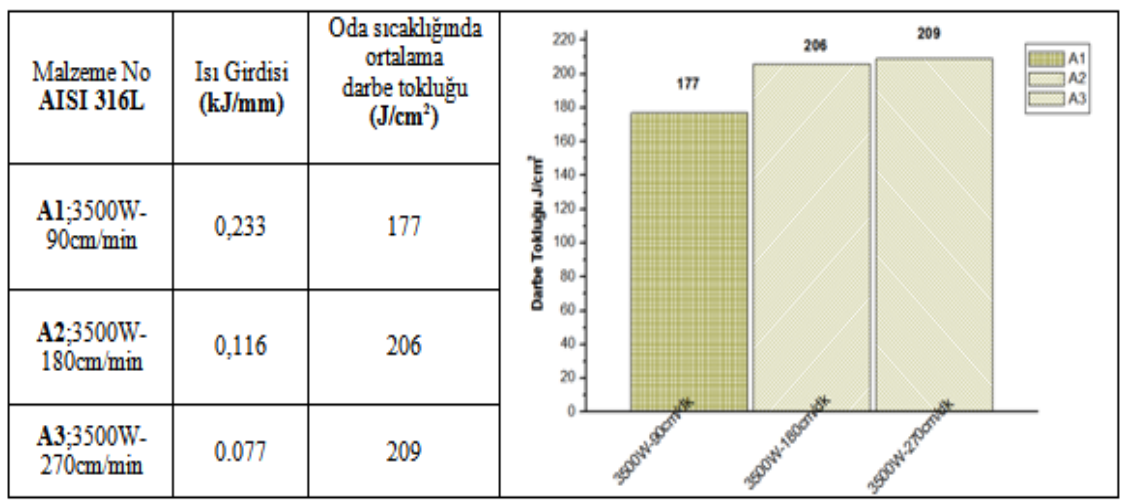

Şekil 11. Darbe V-çentik deneyi sonucu (Results of Charpy V-Notch impact test).
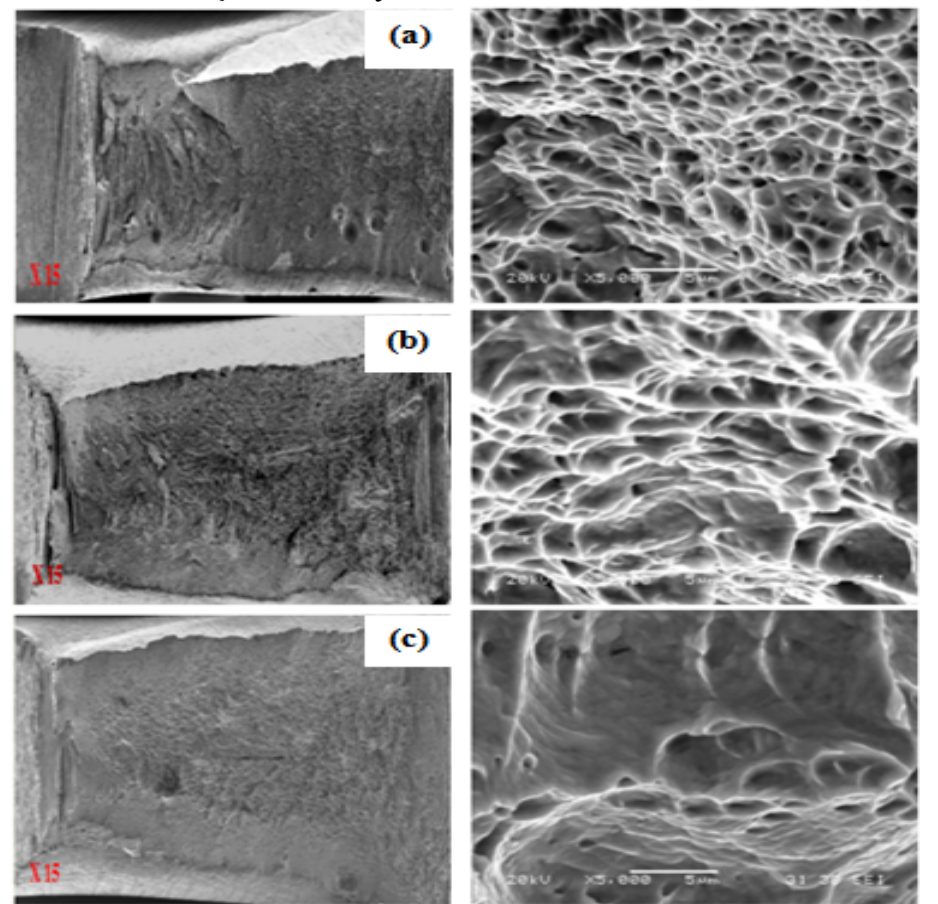

Şekil 12. Çentik darbe deney numunelerinin kırılma yüzeyi SEM görüntüleri (a) $3500 \mathrm{~W}-90 \mathrm{~cm} / \mathrm{min}$, (b) $3500 \mathrm{~W}-180 \mathrm{~m} / \mathrm{min}$, (c) $3500 \mathrm{~W}-270 \mathrm{~cm} / \mathrm{min}$ (The fracture surface of Charpy V-Notch test samples (a) $3500 \mathrm{~W}-90 \mathrm{~cm} / \mathrm{min}$, (b) $3500 \mathrm{~W}-180 \mathrm{~cm} / \mathrm{min}$, (c) $3500 \mathrm{~W}-270 \mathrm{~cm} / \mathrm{min}$ ). 
sünek kırılma davranışı sergileyerek kırıldığı görülmektedir. Artan kaynak ilerleme hızına bağlı olarak azalan 1sı girdisiyle numunelerin yüzeylerinde daha parlak düzgün, düzlemsel tipi ayrılmaların yanısıra meydana gelen çukurların derinliği daha yüzeysel ve çukur içerisinde herhangi inklüzyon oluşmadığı görülmektedir. Çatlak başlangıcına sebep olan bu oluşumların meydana gelmemesi bağlantıların tokluğunu olumlu yönde etkileyen sebeplerden bir tanesidir. Tokluğun iyi olmasına etki eden sebeplerden birisi de yapının yüzey merkez kübik (YMK) kafes yapısına sahip olması sebebiyle şekillendirilebilirliğin iyi olmasından kaynaklanmaktadır.

\section{6. Üç Nokta Eğme Deneyi (Three Point Bending Test)}

Farklı kaynak ilerleme hızları ile birleştirilen numunelerin şekillendirilebilirliği üç nokta eğme deneyi ile belirlenmiştir. Deney sürecinde numuneler $140^{\circ}$ ye kadar katlanmıştır. Kaynak birleştirmelerinde herhangi bir çatlak oluşmamıştır (Şekil 13). Sonuçlar lazer kaynaklı birleştirmelerin servis şartlarında rahatlıkla şekillendirilebileceğine işaret etmektedir.

AISI 316L çeliklerin yapıları itibariyle şekillendirilebilirlikleri oldukça iyidir. Yüksek enerji yoğunluklu, düşük 1Sı girdili kaynak uygulamalarında birleştirmelerin termal süreçlerden daha az etkilenmesi, bu çeliklerin doğası gereği allotropik dönüşüme uğramaması sebebiyle sertliğinin artmaması, çok dar bir ITAB oluşması sebebiyle şekillendirilebilirliğinin iyi olması beklenen bir sonuçtur.

\subsection{Mikrosertlik Ölçüm Sonucu (Microhardness Measurement Result)}

Numunelerin sertlik dağılımları belirlenmiş sonuçlar Şekil 14'de gösterilmiştir. Şekil 14'den görüldüğü gibi kaynak metali ve ITAB sertlikleri birbirine yakın, ana metalin sertliği ise daha düşük bulunmuştur. Kaynak metali sertliğinin ana malzemeye göre daha yüksek bulunmasının sebebi düșük 1sı girdisine bağlı olarak hızlı soğuma ve katılaşma neticesinde elde edilen ince taneli kaynak metali mikroyapısı ile ilişkili olduğu düşünülmektedir.

Literatürde ince taneli kaynak metali sertlik artışının sebebi olarak verilmiştir [20,35]. Ancak, farklı kaynak ilerleme hızının birleştirmelerin kaynak metali ve ITAB sertlik dağılımında belirgin bir etkisi olmadığı bulunmuştur. $\mathrm{Bu}$ beklenen bir durumdur. Çünkü ostenitik paslanmaz çelikler dönüşüme uğramadıkları için yapılarında martenzit gibi sert faz oluşmaması sebebiyle tüm numunelerin kaynak metali sertlik değerleri birbirine yakın bulunmuştur. Literatürde de farklı ısı girdisinin ostenitik paslanmaz çelik kaynak metali ve ITAB sertliğini önemli derecede etkilemediği rapor edilmiştir [12,36].

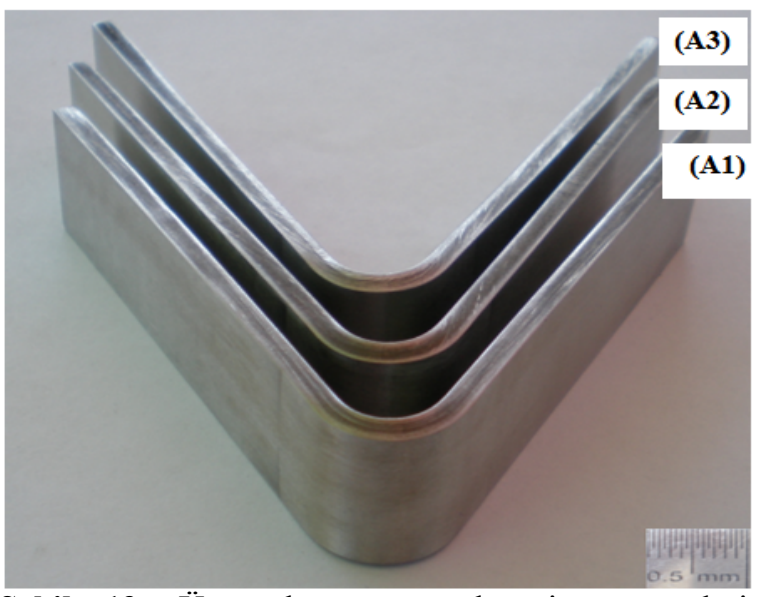

Şekil 13. Üç nokta eğme deneyi numuneleri, A1;3500W-90cm $/ \mathrm{min}, \quad$ A2;3500W $-180 \mathrm{~cm} / \mathrm{min}$, A3;3500W-270 cm/min, (Three point bending test samples A1;3500W-90cm $/ \mathrm{min}, \quad \mathbf{A 2} ; 3500 \mathrm{~W}-180 \mathrm{~cm} / \mathrm{min}, \quad \mathbf{A 3} ; \quad 3500 \mathrm{~W}-$ $270 \mathrm{~cm} / \mathrm{min})$.

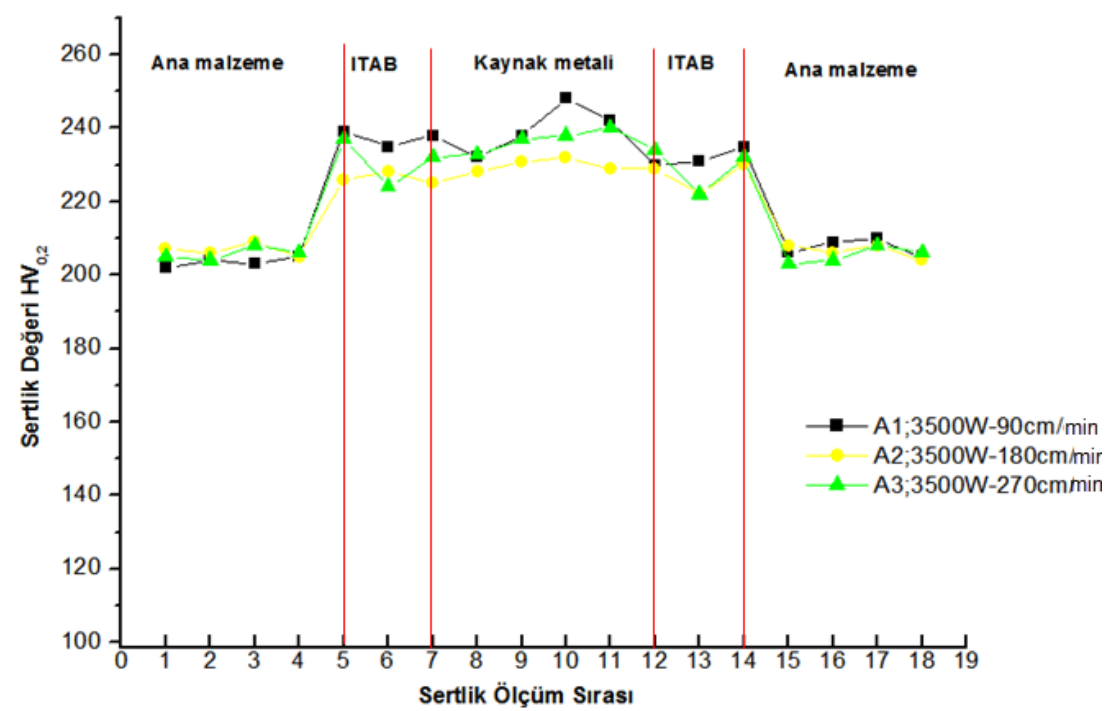

Şekil 14. Numunelerinin sertlik profili (The hardness profile of samples). 


\section{SONUÇLAR (CONCLUSIONS)}

- Kaynak ilerleme hızının kaynak metali mikroyapı morfolojisi üzerinde etkili olduğu bulunmuştur. Düşük kaynak ilerleme hızıyla birleştirilen numunelerde soğuma hızındaki azalmaya paralel olarak kaynak metali içerisindeki karıncalanma tipi delta ferrit morfolojisi yerini yüksek ilerleme hızlarındaki hızlı soğumaya bağlı olarak oluşan çatısal ve çıta tipi ferrite bıraktığı tespit edilmiştir.

- Kaynaklı numunelerin dayanımı ana malzemenin çekme dayanımından daha yüksek bulunmuştur. İlerleme hızının artmasıyla birleştirmelerin çekme dayanımlarının az da olsa iyileştiği görülmektedir. $\mathrm{Bu}$ durum isıdan etkilenen bölgenin daralmasına ve kaynak metali morfolojisinin değişimine yani girintili çıkıntılı ferrit-ostenit tane arayüzeyine atfedilebilir. Böyle arayüzeylerde çatlak ilerlemesi daha düz tane sinırlarına göre güç oluşur.

- AISI 316L birleştirmelerin kaynak metali darbe dayanımının kaynak 1sı girdisi azalmasına bağlı olarak kaynak metali mikroyapı morfolojisinin değişimiyle iyileştiği tespit edilmiştir. Birleştirme üzerinde kalıntı gerilimlerin daha az oluşumu tokluk artışının diğer bir sebebidir.

- Darbe çentik numuneleri sünek kırılma davranışıyla kırıldığı ancak artan kaynak ilerleme hızına bağlı olarak azalan 1sı girdisiyle birleştirilen numunelerin kırılma yüzeylerinde daha parlak düzgün, düzlemsel tipi ayrılmalar tespit edilmiştir.

- Kaynak metali ve ITAB sertlikleri birbirine yakın, ana metalin ise biraz daha düşük bulunmuştur. AISI 316L paslanmaz çelikler 1sıl işlem yoluyla sertleştirilemediklerinden dolayı ilerleme hızının birleştirmelerin sertliğinde etkisi olmadığ bulunmuştur.

- Tüm kaynak ilerleme hızları için birleştirmelerin şekillendirilebilirliklerinin iyi olduğu eğme deneyi ile tespit edilmiştir.

- SEM, EDS, elementel haritalama ve XRD analizleri sonucunda ITAB ve kaynak metalinde alaşım elementi kaybı ve difüzyonuna ve ikincil faz oluşumuna rastlanılmamıştır.

Sonuçlar; endüstride çok geniş bir yelpazede kullanım alanı olan AISI 316L paslanmaz çeliklerin $\mathrm{CO}_{2}$ lazer 1şını kaynak yöntemi ile uygun kaynak parametreleriyle başarılı bir şekilde birleştirilebileceğini, diğer ergitmeli kaynak yöntemleriyle kıyaslandığında birleştirmelerin termal çevrimden daha az etkileneceğine işaret etmektedir. $\mathrm{Bu}$ durum medikal alanda biyo-malzeme olarak da kullanılan AISI 316L birleştirmelerin korozyon özelliklerini de olumlu yönde etkileyeceği düşünülmektedir.

\section{TEŞEKKÜR (ACKNOWLEDGEMENTS)}

$\mathrm{Bu}$ çalışma Karabük Üniversitesi BAP birimince KBÜ-BAP-13/2-DR-009 Numaralı proje kapsamında desteklenmektedir, adı geçen birime teşekkür edilir. Ayrıca, numunelerin lazer kaynaklı birleştirmelerinin yapıldığı Formlaser firmasına teşekkür edilir.

\section{KAYNAKLAR (REFERENCES)}

1. ASM, Introduction to Stainless Steels, Materials Park, Ohio, USA, 2000.

2. Davis, J.R., Stainless Steels, ASM International, OHIO, USA, 1994.

3. Smith, W.F., Paslanmaz Çelikler, Mühendislik Alaşımlarının Yapı ve Özellikleri, Cilt 1, Ankara, 169-214, 2000.

4. Tülbentçi, K., Kaluç, E., Geçmişten Günümüze Paslanmaz Çelikler, META, No 20, 47-52, 1992.

5. Cross, H.J., Beach, J., ve Levy, L.S., Manufacture, Processing and Use of Stainless Steel, Institute of Occupational Health, Birmingham University, B 15 2TT, UK., 1999.

6. Benyounis, K.Y., Olabi, A.G., ve Hashmi, M.S.J., "Multi-Response Optimization of $\mathrm{CO}_{2}$ Laser-Welding Process of Austenitic Stainless Steel", Optics \& Laser Technology, Cilt 40, No 1, 76-87, 2008.

7. Csele, M., Fundamentals of Light Sources and Lasers, John Wiley \& Sons, Hoboken, 2004.

8. Singh, C.S., Zeng, H., Guo, C., ve Cai, W., Lasers: Fundametals, Types and Operations, Nanomaterials: Processing and Characterization With Lasers, First Edition, Wiley-VCH Verlag $\mathrm{GmbH} \& \mathrm{Co} . \mathrm{KGaA}, 2012$.

9. Durmuş, H., $\quad \mathrm{CO}_{2} \quad$ Lazer Kaynağıyla Birleștirilmiş Al. Matriksli Kompozitlerin Kaynak Bölgesinin Mekanik Özellikleri, Doktora Tezi, Celal Bayar Üniversitesi, Fen Bilimleri Enstitüsü, 2006.

10. Kou, S., Welding Metallurgy, Second Editon, A John Wiley \& Sons, INC., Publication, Hoboken, 2003.

11. Çelen, S., "Paslanmaz Çeliklerin Lazer Kaynağında Kaynak Parametrelerinin Bağlantının Dayanım ve Korozyon Özelliklerine Etkisinin İncelenmesi”, Yüksek Lisans Tezi, 9 Eylül Üniversitesi, Fen Bilimleri Enstitüsü, 2006.

12. El-Batahgy, A., "Effect of Laser Welding Parameters on Fusion Zone Shape and Solidification Structure of Austenitic Stainless Steels", Materials Letters, Cilt 32, No 2-3, 155163, 1997.

13. Cunat, $P$., The Welding of Stainless Steel, Materials and Applications Series, Cilt 3, Second Edition, Euro Inox, Cilt, Luxembourg, 2007.

14. Balasubramanian, K.R., Siva Shanmugam, S., ve Buvanashekaran G., "Numerical and 
Experimental Investigation of Laser Beam Welding of AISI 304 Stainless Steel, Advences and Production Engineering \& Management, Cilt 3, No 2, 93-105, 2008.

15. Duley, W. W., Laser Processing and Analysis of Materials, Plenum Press, New York, 1983.

16. Pawlak, S.J. ve Dudek, S., "The High Alloy Precipitation Hardening Martensitic Steels and Their Suitability for Welding", Archives of Materials Science and Engineering, Cilt 41, No 2, 69-76, 2010.

17. Ren, D., Liu, L., ve Li, Y., "Investigation on Overlap Joining of AZ61 Magnesium Alloy: Laser Welding, Adhesive Bonding, and Laser Weld Bonding" Int J Adv Manuf Technol, Cilt 61, No 1-4, 195-204, 2012.

18. Ventrella, A., Berretta, J.R., ve Rossi, W., "Pulsed Nd:YAG Laser Seam Welding of AISI 316L Stainless Steel Thin Foils", Journal of Materials Processing Technology, Vol 210, No 14,2010

19. Missori, S. ve Koerber, C., "Laser Beam Welding Austenitic-Ferritic Transition Joints", Welding Research Supplement, Cilt 76, No 3, 1997.

20. Kwok, C.T., Fong, S.L., Cheng, F.T ve Man, H.C., "Pitting and Galvanic Corrosion Behavior of Laser-Welded Stainless Steels", Journal of Materials Processing Technology, Cilt 176, No 1-3, 168-178., 2006.

21. Köse, C. ve Kaçar, R., "Mechanical Properties of Laser Welded 2205 Duplex Stainless Steel", Materials Testing, Cilt 56, No 10, 779-785, 2014.

22. Köse, C. ve Kaçar, R., "The Effect of Preheat \& Post Weld Heat Treatment on the Laser Weldability of AISI 420 Martensitic Stainless Steel", Materials and Design, Cilt 64, 221-226, 2014.

23. Dadfar, M., Fathi, M.H., ve Saatchi, A., "Effect of TIG Welding on Corrosion Behavior of $316 \mathrm{~L}$ Stainless Steel", Materials Letters, Cilt 61, No 11-12, 2343-2346, 2007.

24. Samanta, S.K., Mitra, S.K., ve Pal, T.K., "Microstructure and Oxidation Characteristics of Laser and GTAW Weldments in Austenitic Stainless Steels", JMEPEG, Cilt 17, No 6, 908914, 2008.

25. Venkataraman, S. ve Devletian, H., "Rapid Solidification of Stainless Steels by Capacitor Discharge Welding", Supplement to The Welding Journal, AWS Welding Research, Cilt 67, No 6, June 1988.
26. ASM Handbook, Welding, Brazing and Soldering, ASM International, Cilt 6, 1187, 1993.

27. Gill, T.P.S., Vijayalakshmi, M., Gnanamoorthy, J.B., ve Padmanabhan, K.A., "Transformation of Delta-Ferrite during the Postweld Heat Treatment of Type 316L Stainless Steel Weld Metal", Welding Research Supplement, Cilt 65, No 5, 1986.

28. Inoue, H., Koseki, T., Okhita, S., ve Tanaka,T., "Effect of Solidification and Subsequent Ferrite to Austenite Massive Transformation in an Austenitic SS Weld Metal”, ISIJ Int., Cilt 35, No 10, 1995.

29. Sutala, N., Takalo T., ve Moisio,T., FerriticAustenitic Solidification Mode in Austenitic Stainless Steel Welds, Met. Trans. A, Cilt 11, No 5, 1980 .

30. Leone, G.L., ve Kerr, H.W., "The Ferrite to Austenite Transformation in Stainless Steels", Welding Research Supplement, Cilt 61, No 1, 1982.

31. Shankar, V., Gill, T.P.S., Mannan, S.L., ve Sundaresan, S., "Solidification Cracking in Austenitic Stainless Steel Welds, $\boldsymbol{S}^{-} \boldsymbol{a d h a n}{ }^{-} \boldsymbol{a}$, Cilt. 28, No 3-4, 359-382, 2003.

32. Olson, D.L., "Prediction of Austenitic Weld Metal Microstructure and Properties", Welding Research Supplement, Cilt 64, No 10, 1985.

33. Lippold, J.C., ve Kotecki, D.J., "Welding Metallurgy and Weldability of Stainless Steels", John Wiley and Sons, 2005.

34. Ibrahim, O., Ibrahim, S., ve Khalifa, T.A.F.," Effect of Aging on the Toughness of Austenitic and Duplex Stainless Steel Weldments", J.Mater. Sci. Technol., Cilt 26, No 9, 810-816, 2010.

35. Sathiya, P. ve Jaleel, A., "Measurement of the Bead Profile and Microstructural Characterization of a $\mathrm{CO}_{2}$ Laser Welded AISI 904L Super Austenitic Stainless Steel”, Optics \& Laser Technology, Cilt 42, No 6, 960-968, 2010.

36. Uzun, R.O. ve Keleş, Ö., "Investigation Effect on Welding Quality of Laser Welding Parameters", Journal of the Faculty of Engineering and Architecture of Gazi University, Cilt 27, No 3, 509-517, 2012.

37. Çam, M., Erim, S., ve Koçak, M., "Determination of Mechanical and Fracture Properties of Laser Beam Welded Steel Joints", Supplement to The Welding Journal, AWS Welding Research, Cilt 78, 193, 1999. 
